\title{
New Propellant Component, Part I. Study of 4,6-Dinitroamino-1,3,5-Triazine-2(1 H)-One (DNAM)
}

\author{
P. Simões*, L. Pedroso, and A. Portugal \\ LEDAP_Laboratory of Energetics and Detonics, Chemical Engineering Department, Faculty of Sciences \\ and Technology, University of Coimbra, 3030-290 Coimbra (Portugal)
}

\section{P. Carvalheira and J. Campos}

LEDAP_Laboratory of Energetics and Detonics, Mechanical Engineering Department, Faculty of Sciences and Technology, University of Coimbra, 3030-290 Coimbra (Portugal)

\section{Summary}

This paper reports a study of the synthesis and characterization of 4,6-dinitroamino-1,3,5-triazine-2 $(1 \mathrm{H})$-one (DNAM) carried out under the perspective of looking for new ingredients in propellant formulations. Emphasis is given to the characterization of DNAM. The following attributes were identified: low sensitivity to impact and friction, thermal stability over a wide temperature range, energetic nature, high density, and interesting particle size distribution. In Part 2 a preliminary evaluation of DNAM capabilities in a propellant formulation will be presented.

\section{Introduction}

The quest of new energetic materials for use in propellant formulations is a continuous challenge. Usually, high performances are constrained by safety considerations, whose meaning is wider than before. Not only low vulnerability requirements are necessary, but also important demands concerning environmental impact of the combustion products are being a matter of investigation ${ }^{(1-4)}$. The search of alternative propellant ingredients for replacing the wellknown Ammonium Perchlorate (AP) based compositions became a common issue in the field. However, it has been argued that the development of new energetic materials typically exhibits a lack of a logical and systematic approach to the needed characterization of the new materials ${ }^{(5)}$. This is a pertinent question, made more relevant by the cost associated with the development of new energetic molecules.

In the light of the above considerations, a work program was defined according to which, instead of developing a completely new halogenous free target molecule, priority to the search of an acceptable alternative was given. The nitrated derivative of 2,4,6-triamino-s-triazine (melamine), known as dinitroammeline (DNAM), has been reported for the first time in $1951^{(6)}$. However, this compound has never been deeply studied within the framework of propellants. This paper reports the study on the compound 4,6-bis

\footnotetext{
* Corresponding author; e-mail: pnsim@eq.uc.pt
}

(nitroamino)-1,3,5-triazine-2(1 H)-one (and/or its tautomeric forms) developed from the established nitration of melamine, highlighting the characterization of the product. The study started four years ago ${ }^{(7)}$, has permitted us to clarify the main DNAM attributes and therefore has opened new avenues for its application.

\section{Synthesis of DNAM}

Besides the nitration procedure, relevant informationalready available on dinitroammeline characteristics when we started our study — can be quoted as follows ${ }^{(6)}$ : it decomposes sharply without melting at $228^{\circ} \mathrm{C}$; the measured heat of combustion $1519.67 \mathrm{~kJ} \mathrm{~mol}^{-1}$; and a two-step curve was obtained from an electrometric titration with $\mathrm{NaOH}$.

DNAM was then synthesized according to the established method by the nitration of melamine with an acetonitric mixture:

The purity of the nitrated product was checked by elemental analysis (Fisons EA1180). Typical results are as follows: Anal. Calcd. for $\mathrm{C}_{3} \mathrm{H}_{3} \mathrm{O}_{5} \mathrm{~N}_{7}$ : C $16.60 \%$; $\mathrm{H} 1.39 \%$; N 45.16\%. Found: C 16.31\%, 16.45\%; H 1.51\%, 1.45\%; $\mathrm{N} 45.10 \%, 45.05 \%$.<smiles>C=C=C([N+](=O)[O-])[N+](=O)[O-]</smiles>

Scheme 1 
Once the original synthesis and purification routes have been successfully reproduced, the main goal was directed to the characterization of pure DNAM.

\section{Characterization of DNAM}

\subsection{Chemical Properties}

\subsubsection{Spectroscopic Analysis}

IR spectroscopy (Nicolet 750) was used to identify the molecular structure of DNAM. This study (see Figure 1) has shown that in the solid state, among the possible tautomeric configurations, the keto forms 4,6-dinitroamino-1,3,5triazine-2(1 H)-one and 4,6-dinitroamino-1,3,5-triazine$2(5 \mathrm{H})$-one prevail over the enol form 4,6-dinitroamino1,3,5-triazine-2-ol (see Eq. (1), i.e. Scheme 1). The presence of nitro groups is identified by the intense signals at 1600 and $1250 \mathrm{~cm}^{-1}$. The band around $3200 \mathrm{~cm}^{-1}$ is assigned to the monosubstituted amino group. This is also revealed by the absence of absorption in the region $1680-1640 \mathrm{~cm}^{-1}$, typical of nonsubstituted $\mathrm{NH}_{2}$ groups in this kind of systems. The predominance of keto forms is clearly shown by the presence of the strong absorption near $1770 \mathrm{~cm}^{-1}$ due to the $\mathrm{C}=\mathrm{O}$ group. Also, the signal around $760 \mathrm{~cm}^{-1}$ is typical when the triazine is in the iso form, i.e., with less then three double bonds in the ring and at least one double bond external to the ring $^{(8)}$.

\subsubsection{Acidity}

A three-step curve was found by potentiometrically titrating (Metrohm-736 GP Titrino) DNAM, in ca. $0.001 \mathrm{~mol} \cdot 1^{-1}$ aqueous solution, with $0.1 \mathrm{~mol} \cdot 1^{-1} \mathrm{NaOH}$, at room temperature. As a first approximation, the Henderson-Hasselbalch equation ${ }^{(9)}$ was used to calculate the $p K_{a}$ corresponding to the first dissociation of DNAM, whose value was found to be 3.2. This figure confirms an acidity character that could be anticipated from the primary nitra-

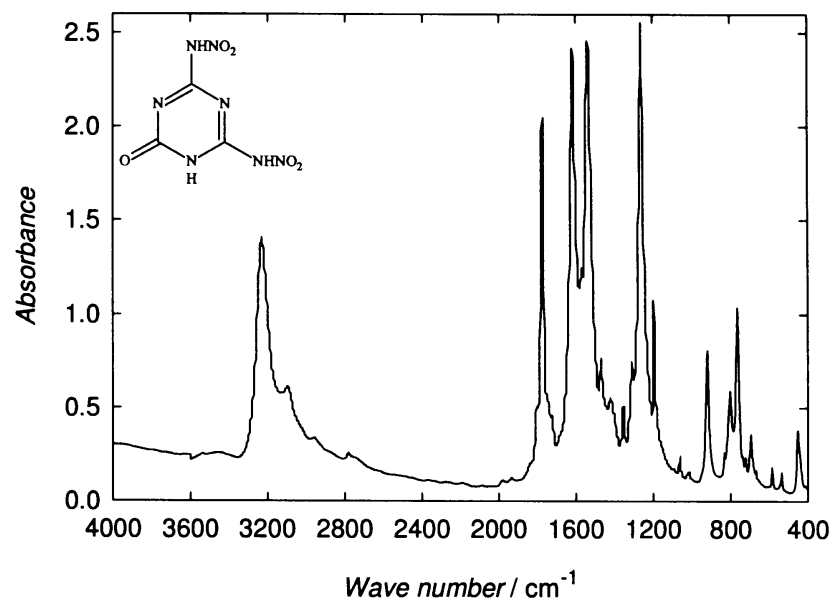

Figure 1. FTIR of DNAM. mino groups in DNAM. Such an acidity should be taken into account in compatibility and ageing issues in formulating studies. Parallel considerations should be given to the decomposition of DNAM in aqueous solutions, which is a matter being investigated.

\subsection{Hazard Properties}

Impact and friction sensitivity, and vacuum thermal stability tests were performed. Characteristic results of these measurements are summarized in Table 1. DNAM presents good safety attributes; for instance, in comparative terms, it appears to be less sensitive than an explosive such as HMX.

\subsection{Physical Properties}

Physical properties of DNAM such as density, specific surface area, and particle size distribution were measured. Table 2 resumes the results of these measurements, and Figure 2 presents typical DNAM particle size distributions and particle shape.

It was possible to have a first estimate for the density of DNAM by using the Stine's algorithm ${ }^{(10)}$. A predicted value of $1.916 \mathrm{~g} \mathrm{~cm}^{-3}$ was the first indication on the high density of DNAM, of which confirmation is given by the measured value of $1.949 \mathrm{~g} \mathrm{~cm}^{-3}$. The low value for the powder specific surface area indicates a non-porous material.

As shown in Figure 2, the particle size distribution of DNAM seems to be prone to some variations from batch to batch, although within certain limits. This can be due to some operating factors during the purification stage, and/or to a non-uniform (slight) grinding of the solid samples (a pestle and a mortar were used) necessary to avoid the formation of particle aggregates. It should be mentioned that the actual particle size(s) and correspondent mean value(s) are

Table 1. Hazard and Thermal Stability Properties of DNAM

\begin{tabular}{lll}
\hline Property under study & Method & Result \\
\hline Impact sensitivity & BAM test & $>50.5 \mathrm{~J}$ \\
Friction sensitivity & BAM test & $>360 \mathrm{~N}$ \\
Vacuum thermal stability & $40 \mathrm{~h}$ at $100{ }^{\circ} \mathrm{C}$ & $0.257 \mathrm{~cm}^{3} \mathrm{~g}^{-1}$ \\
\hline
\end{tabular}

Table 2. Some Physical Properties of DNAM

\begin{tabular}{lll}
\hline Property & Technique & Value \\
\hline$\rho / \mathrm{g} \mathrm{cm}^{-3}$ & $\begin{array}{l}\text { Gas (Helium) picnometry } \\
\text { (Micrometrics-AccuPyc1330) }\end{array}$ & $1.949 \pm 0.002 *$ \\
$\mathrm{~S} / \mathrm{m}^{2} \mathrm{~g}^{-1}$ & $\begin{array}{l}\text { Multipoint BET } \\
\text { (Micrometrics-ASAP2000) }\end{array}$ & 1.091 \\
$d_{50} / \mu \mathrm{m}$ & $\begin{array}{l}\text { Laser diffraction with PIDS } \\
\text { (Coulter LS130) }\end{array}$ & $2.55-7.97$ \\
\hline
\end{tabular}

* Mean of 29 measurements. (The uncertainties are referred to a confidence level of $95 \%$; this note applies along the paper). 


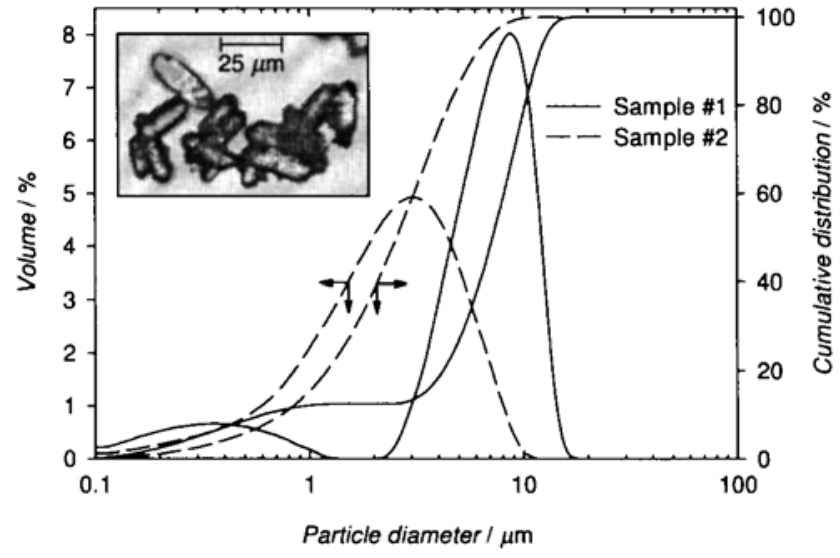

Figure 2. Typical particle shape and size distributions of DNAM.

expected to be somewhat higher than those exhibited by the distribution curves in Figure 2 and the $d_{50}$ values in Table 2 . The output of the laser diffraction technique from which these are derived is based on the mean diameter of the randomly projected area instead of the maximum projected area as it is in image analysis ${ }^{(11)}$. In fact, the image analysis picture also shown in Figure 2 indicates that a particle size analysis made by this technique would appear somewhat shifted towards higher sizes.

\subsection{Thermophysical Properties}

\subsubsection{Heat of Combustion and Standard Enthalpy of} Formation

The measurement of the heat of combustion was performed in an oxygen bomb calorimeter (Parr 1271) and a value of $1508.11 \pm 14.79 \mathrm{~kJ} \mathrm{~mol}^{-1}$ (mean of 6 measurements) was obtained. The standard enthalpy of formation $\left(\Delta H_{f}^{o}\right.$ at $\left.298 \mathrm{~K}\right)$ was calculated according to Ref. 12 and a value of $-111.21 \mathrm{~kJ} \mathrm{~mol}^{-1}$ was found.

\subsubsection{Heat Capacity}

The heat capacity at constant pressure has been measured by DSC (Perkin-Elmer - DSC7), leading to the values of 0.984 and $1.176 \mathrm{~J} \mathrm{~K}^{-1} \mathrm{~g}^{-1}$ at $35^{\circ} \mathrm{C}$ and $75^{\circ} \mathrm{C}$, respectively.

\subsubsection{Thermal Analysis}

The thermal behavior of DNAM was studied with some detail by means of simultaneous thermal analysis (STA) ${ }^{(13)}$. Typical thermoanalytical curves are presented in Figure 3. It was concluded that DNAM presents good thermal stability, without solid/solid transitions neither melting in the wide temperature range that precedes the exothermic thermolysis. This starts in the range $215-230^{\circ} \mathrm{C}$ according to the conditions of the study (Rheometric Scientific - STA 1500 equipment, sample mass of ca. $\sim 2 \mathrm{mg}, \mathrm{N}_{2}$ as purge gas, and heating rates from 2.5 to $20^{\circ} \mathrm{C} \mathrm{min}^{-1}$ ). As shown

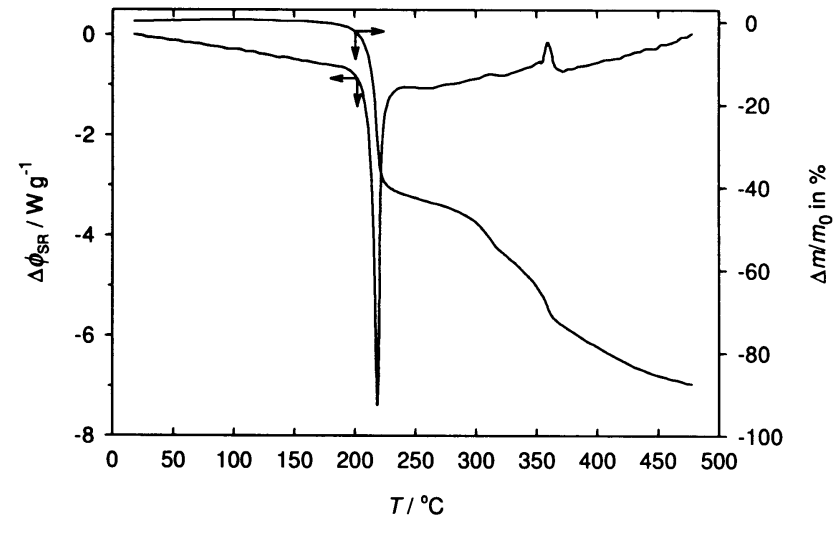

(a) Typical DSC and TG curves at $2.5^{\circ} \mathrm{Cmin}^{-1}$.

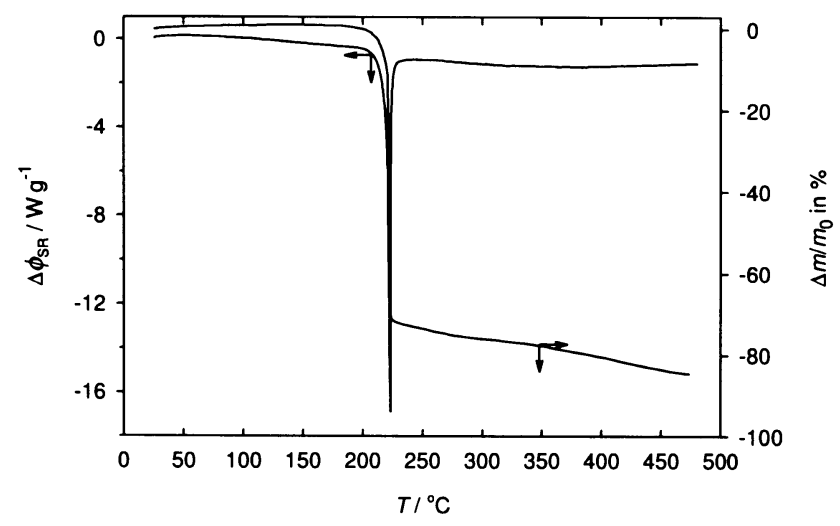

(b) Typical DSC and TG curves at $5^{\circ} \mathrm{C} \mathrm{min}^{-1}$.

Figure 3. Thermoanalytical curves for DNAM.

in Figure 3, the thermolysis occurs in a sharper way for heating rates equal or higher than $5^{\circ} \mathrm{Cmin}^{-1}$ as a consequence of the sample auto-ignition followed by a thermal runaway.

The Arrhenius parameters of the decomposition process were estimated using as a first approach the ASTM method $^{(14,15)}$, which assumes a "first order" reaction kinetic model $f(\alpha)=(1-\alpha)$ (see below) for the preexponential factor, $A$, determination. The calculated values (for an approximate temperature range $220-235^{\circ} \mathrm{C}$ ) were $269 \mathrm{~kJ} \mathrm{~mol}^{-1}$ and $2.5 \cdot 10^{26} \mathrm{~s}^{-1}$ for $E_{A}$ and $A$, respectively ${ }^{(13)}$. Improved results were obtained recently by applying a more reliable methodology for the kinetic analysis of solid state reactions as described below.

The start equation for kinetic data evaluation is the wellknown expression for the rate of the process in which it is assumed that the temperature dependence $k(T)$ is given by the Arrhenius expression,

$$
\frac{d \alpha}{d t}=k(t) \cdot f(\alpha)=A \cdot e^{-\frac{E_{A}}{R \cdot T}} \cdot f(\alpha)
$$

where $\alpha$ is the degree of conversion, $E_{A}$ the activation energy, $A$ the pre-exponential factor, $T$ the absolute temperature, $R$ 
the gas constant, $t$ the time, and $f(\alpha)$ the kinetic model function based on the physico-geometric assumption of the reaction interface movement ${ }^{(16)}$. Applying logarithms to Equation (2) results

$$
\ln \left(\frac{d \alpha}{d t}\right)=\ln (A \cdot f(\alpha))-\frac{E_{A}}{R \cdot T}
$$

Equation (3) permits to estimate the value of $E_{A}$ without any assumption other than the rate of the process being described by the Arrhenius law ${ }^{(17,18)}$. The concept of generalized time, $\tau$, proposed by Ozawa ${ }^{(19,20)}$, allows Equation (3) to be expressed as the reaction rate at infinite temperature ${ }^{(21)}$.

$$
\frac{d \alpha}{d \tau}=A \cdot f(\alpha)
$$

The kinetic analysis of the thermolysis of DNAM was restricted to the beginning of the exothermic event (temperature range $200-225^{\circ} \mathrm{C}$ ). A mass loss value far enough from the auto-ignition of the sample was fixed after a careful analysis of the thermoanalytical curves of all runs performed at different heating rates. That value was used as a reference for normalizing the TG curves in order to determine the correspondent degree of conversion values, $\alpha$, ranging from 0 to 1 . Thus, it should be noted that this range of $\alpha$ corresponds only to the beginning of the mass loss instead of the overall mass loss of the exothermic event.

The $E_{A}$ as a function of $\alpha$ was obtained applying Equation (3) at different conversion levels. The constancy of $E_{A}$ with $\alpha$ is a fundamental requisite underlying the method. This condition is fulfilled in good approximation for the case under study, as shown in Figure 4.

Taking the mean value $239 \mathrm{~kJ} \mathrm{~mol}^{-1}$ for $E_{A}$ from the results of Figure 4, and applying an adequate methodology ${ }^{(21,22)}$, it was found that the first stage of the thermolysis of DNAM is well described by the power law model $f(\alpha)=2 \cdot \alpha^{1 / 2}$. Once obtained $\alpha$, the value of $A$ was calculated according to Equation (4) and its invariance with $\alpha$ was checked as shown in Figure 4. An approximate constant value was found in almost every conversion range. This check has been made for each heating rate, leading to mean values (calculated for $\alpha \geq 0.10$ ) of $A$ in the range form $8.9 \cdot 10^{23} \mathrm{~s}^{-1}$ to $10.6 \cdot 10^{23} \mathrm{~s}^{-1}$. Finding a range of $A$ instead

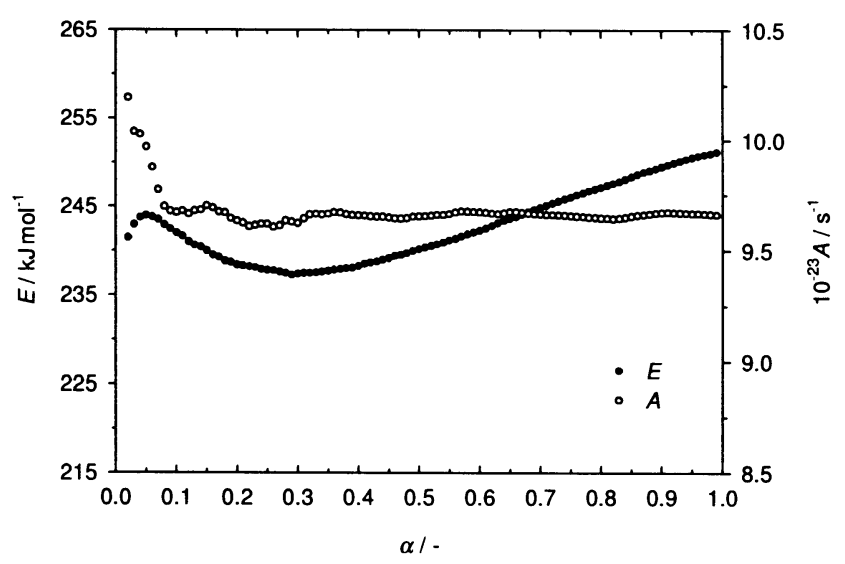

Figure 4. E and $\mathrm{A}$ as a function of $\alpha$. of a single value is understandable in the light of the kinetic compensation effect known in the context of the kinetic analysis of solid state reactions ${ }^{(23)}$.

Finally, the adequacy of the kinetic analysis results in describing that the process was verified comparing the predicted with the experimental results as shown in Figure 5. The good agreement is noticeable and deserves further comments. The kinetic model found has a physicogeometric background giving some theoretical basis for interpreting the process instead of a purely empirical one.

The power law is the simplest kinetic expression resulting from the modeling of the reacting interface advance. Its validity is limited to the early stages of the reaction, when the hypothesis of the formation and growth of unrestricted nucleation can be applied ${ }^{(24)}$. On the other hand, the power law is usually ascribed to processes in which the rate of incorporation of the reactant species in the reaction interface appears to be the limiting step in the overall growth process ${ }^{(16)}$. It should be remembered that the performed kinetic analysis of the thermolysis of DNAM was restricted just to the very early stage.

It is of interest to place the thermolysis of DNAM in the perspective of other works carried out on the decomposition of nitramines ${ }^{(25-29)}$. It is generally accepted that nitramine functional group is predominant in the early decomposition stages. It is the main source of highly reactive species as, among others, nitrogen oxides such as $\mathrm{NO}_{2}$ and/or $\mathrm{N}_{2} \mathrm{O}$, whose relative amounts are dependent on factors like temperature, pressure, and structure of the starting nitramine ${ }^{(25,29)}$. These reactive species are crucial as reaction proceeds, namely because they are the only oxygen suppliers when no other (external) oxygen source is available. Our kinetic analysis results are qualitatively consistent within this framework of the thermolysis of nitramines. In the light of experimental evidences showing that primary nitramines are strong generators of $\mathrm{N}_{2} \mathrm{O}$ when compared with secondary ones $^{(29)}$, it is our belief that the primary nitramine groups in DNAM would preferentially generate $\mathrm{N}_{2} \mathrm{O}$ in the early decomposition stages. But the first species actually formed in the reaction interface remain to be identified, and a deeper research on the decomposition of DNAM will be necessary.

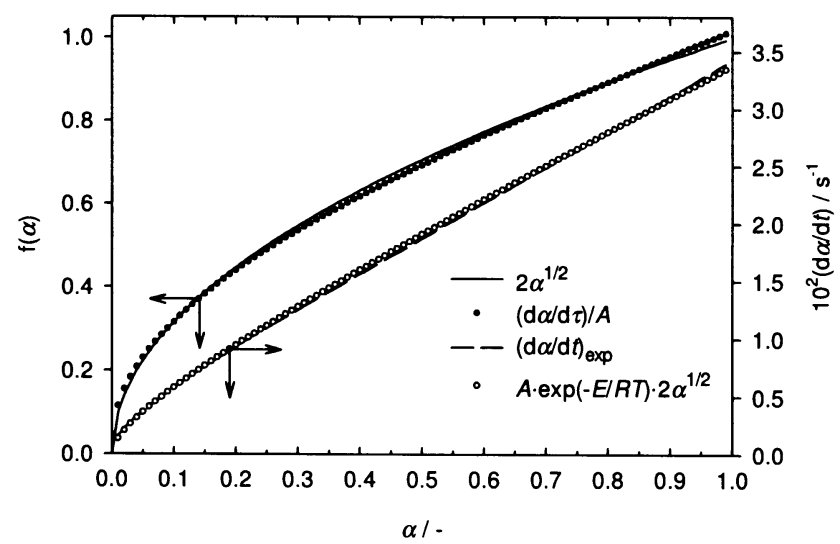

Figure 5. Checking the validity of the kinetic analysis of the first stage of the thermolysis of DNAM. 


\section{Conclusions}

Being a halogen free compound, exhibiting low sensitive to impact and friction, DNAM fulfils basic requirements from the safety point of view. Its expected acidic character should be cautiously faced in formulating studies.

DNAM is a high density material, and measured particle size distribution appears advantageous in the perspective of its use as a propellant ingredient: the relatively small size of DNAM particles would be a relevant attribute in terms of processability, attainable higher solid loadings, and better burning characteristics.

The thermoanalytical measurements revealed not only the thermal stability of DNAM in a wide temperature range, within which solid/solid phase transitions and melting are absent, but also its energetic nature expressed by a sharp exothermic reaction characterizing the thermolysis. The kinetic study directed to the early stage of this reaction led to interesting results, whose consistency with other published results on the thermolysis of nitramines should be taken into account in future studies for a better phenomenological understanding of the decomposition of DNAM.

More work will be necessary for the full characterization of DNAM. Nevertheless, the information already available justifies a parallel evaluation of the DNAM potential as a propellant ingredient. The work developed in this context is reported in Part 2 of this paper.

\section{References}

(1) R. R. Bennett, J. R. Whimpey, R. Smith-Kent, and A. J. McDonald, "Effects of Rocket Exhaust on the Launch Site Environment Stratospheric Ozone", in: K. K. Kuo (ed.), "Challenges in Propellants and Combustion", Begell House, New York 1997, pp. 92-104.

(2) C. W Hawk, "Environmental Effects of Solid Rocket Propellants, Perceptions and Realities", in: "Environmental Aspects of Rocket and Gun Propulsion" AGARD Conference Proceedings 559, Neuilly sur Seine 1995, pp. K/1-K/8.

(3) A. J. McDonald and R. R. Bennett, "Environmental Impacts From Launching Chemical Rockets", in: "Environmental Aspects of Rocket and Gun Propulsion" AGARD Conference Proceedings 559, Neuilly sur Seine 1995, pp. 1.1-8.12.

(4) A. P. Tishin and E. L. Alexandrov, "The Impact of Space Rocket Launches on the Earth Ozone Layer", in: "Environmental Aspects of Rocket and Gun Propulsion" AGARD Conference Proceedings 559, Neuilly sur Seine 1995, pp. 2.1-2.8.

(5) A. Sanderson, "The Characterization and Development of New Energetic Materials", 27th Int. Annual Conference of ICT, Karlsruhe, Germany, June 25-28, 1996, pp. 18.1-18.8.

(6) E. R. Atkinson, "The Nitration of Melamine and Triacetylmelamine", J. Am. Chem. Soc. 73, 4443-4444 (1951).

(7) P. Simões, P. Carvalheira, A. Portugal, J. Campos, L. Durães, and J. Góis, "Characterization of 2-Oxy-4,6-Dinitramine-s-Triazine", 27th Int. Annual Conference of ICT, Karlsruhe, Germany, June 25-28, 1996, pp. 136.1-136.13.

(8) N. B. Colthup, L. H. Daly, and Wiberley, "Introduction to Infrared and Raman Spectroscopy", Academic Press, New York 1975.
(9) P. W. Atkins, "Physical Chemistry" 5th ed., Oxford University Press, New York 1994, pp. 291-307.

(10) S. R. Stine, "Prediction of Crystal Densities of Organic Explosives by Group Additivity”, Technical Report LA-8920 (1981), Los Alamos National Laboratory, Los Alamos, NM, USA.

(11) F. M. Barreiros, P. J. Ferreira, and M. M. Figueiredo, "Calculating Shape Factors from Particle Size Data", Part. Part. Syst. Charact. 13, 368-373 (1896).

(12) P. E. Rouse, Jr., "Enthalpies of Formation and Calculated Detonation Properties of Some Thermally Stable Explosives", J. Chem. Eng. Data 21(1), 16-20 (1976).

(13) P. Simões, A. Portugal, and J. Campos, "Thermal Decomposition and Kinetic Analysis of the Thermal Decomposition of 2-Oxy4,6-Dinitramine-s-triazine in Non-Isothermal Conditions", Thermochimica Acta 298, 95-108 (1997).

(14) ASTM E698-79, "Test Method for Arrhenius Kinetic Constants for Thermally Unstable Materials", 1979 (rev. 1993).

(15) T. Ozawa, "Kinetic Analysis of Derivative Curves in Thermal Analysis", J. Thermal Anal. 2, 301-324 (1970).

(16) J. Sesták, "Thermophysical Properties of Solids-Their Measurements and Theoretical Analysis", in: G. Svehla (ed.), "Thermal Analysis", Vol. 12 of "Comprehensive Analytical Chemistry-Part D”, Elsevier, Amsterdam 1984, pp. 183-196.

(17) T. Ozawa, "Non-Isothermal Kinetics and Generalized Time", Thermochimica Acta 100, 109-118 (1986).

(18) T. Ozawa, "Estimation of Activation Energy by Isoconversional Methods", Thermochimica Acta 203, 159-165 (1992).

(19) T. Ozawa, "Applicability of Friedman Plot", J. Thermal Analysis 31, 547-551 (1986).

(20) T. Ozawa, "A New Method of Analyzing Thermogravimetric Data", Bul. Chem. Soc. Japan. 38(11), 1881-1886 (1965).

(21) N. Koga, "Kinetic Analysis of Thermoanalytical Data by Extrapolating to Infinite Temperature", Thermochimica Acta 258, 145-159 (1995).

(22) J. Málek, "The Kinetic Analysis of Non-Isothermal Data", Thermochimica Acta 200, 257-269 (1992).

(23) N. Koga, "A Review on the Mutual Dependence of Arrhenius Parameters Evaluated by the Thermoanalytical Study of Solid State Reactions: The Kinetic Compensation Effect", Thermochimica Acta 244, 1-20 (1994).

(24) A. K. Galwey and M. E. Brown, "Kinetic Background to Thermal Analysis and Calorimetry", in: M. E. Brown (ed.), "Principles and Practice", Vol. 1 of "Handbook of Thermal Analysis and Calorimetry", chapter 3. Elsevier, Amsterdam (1998).

(25) T. B. Brill, "Connecting the Chemical Composition of a Material to its Combustion Characteristics", Prog. Energy Combust. Sci. 18, 91-116 (1992).

(26) M. H. Alexander, P. J. Dagdigian, M. E. Jacox, C. E. Kolb, C. F. Melius, H. Rabitz, M. D. Smooke, and W. Tsang, "Nitramine Propellant Ignition and Combustion Research", Prog. Energy Combust. Sci. 17, 263-296 (1991).

(27) C. F. Melius, "Thermochemical Modeling: I. Application to the Decomposition of Energetic Materials", in: S. N. Bulusu (ed.), "Chemistry and Physics of Energetic Materials", Kluwer Academic Press Publishers, The Netherlands 1990, pp. 21-49.

(28) J. S. Murray and P. Politzer, "Structure-Sensitivity Relationships in Energetic Compounds", in: S. N. Bulusu (ed.), "Chemistry and Physics of Energetic Materials", Kluwer Academic Press Publishers, The Netherlands 1990, pp. 157-173.

(29) T. B. Brill, "Structure-Thermolysis Relationships for Energetic Materials", in: S. N. Bulusu (ed.), "Chemistry and Physics of Energetic Materials", Kluwer Academic Press Publishers, Netherlands 1990, pp. 277-326.

(Received December 12, 1999; Ms 1999/79) 